\title{
Duas espécies novas de Brunettia Annandale (Diptera, Psychodidae) da Bahia, nordeste do Brasil
}

Freddy Bravo ${ }^{1}$

\begin{abstract}
Two new species of Brunettia Annandale (Diptera, Psychodidae) from Bahia, northeast of Brazil. Two new species of Psychodidae, Brunettia soteropolitana sp. nov. and Brunettia itabunensis sp. nov. from Bahia, northeast of Brazil are described.

KEY WORDS. Diptera, Psychodidae, Brunettia, new species, Brazil
\end{abstract}

São conhecidas cinco espécies de Brunettia Annandale, 1910 da região neotropical (BRAVO \& AMORIM 1995; QUATE 1996, 1999; BRAVO 2001). Três espécies foram descritas da América Central, B. acutala Quate, 1999 do Panamá, B. apiculata Quate, 1996 e B. bistria Quate, 1996 da Costa Rica. As outras duas espécies foram descritas do Brasil, uma do sudeste, B. caipira Bravo \& Amorim, 1995 e a outra, B. bora Bravo, 2001, da Bahia. Neste trabalho, descrevem-se duas espécies novas da Bahia, uma do sul do estado e outra de Salvador.

\section{MATERIAL E MÉTODOS}

Os exemplares estudados foram tratados com solução aquosa de hidróxido de potássio $(\mathrm{KOH})$ e montados em lâmina permanente para seu estudo. Os exemplares estão depositados na Coleção Entomológica da Universidade Estadual de Feira de Santana (CUFS), Feira de Santana, Bahia. A nomenclatura usada para a descrição das espécies é a mesma usada em BRAVo \& AMORIM (1995) e BRAVO (2001).

\section{Brunettia itabunensis sp. nov. Figs 1-7}

Material-tipo. Holótipo macho. BRASIL, Bahia: Itabuna, 30.I.1999, J.R.M. Santos leg. (CUFS). Parátipos: 2 machos com mesma etiqueta do holótipo (CUFS); 1 macho da mesma localidade e coletor do holótipo, 30.V.1999 (CUFS).

Etimologia. O nome da espécie é alusivo à cidade onde os espécimes foram coletados.

Diagnose. Sc pouco esclerotinizada. CuA normal. $\mathrm{R}_{1}$ quebrada na base. Placa pós-hipandrial larga na base. Apice do esternito 10 terminando em ponta. Parâmeros com curvatura apical. Base do apódema ejaculador largo, subtriangular.

Holótipo macho. Tegumento preto. Comprimento do corpo, desde o inicio do tórax até o final do abdôme, $1,39 \mathrm{~mm}$.

1) Departamento de Ciências Biológicas, Universidade Estadual de Feira de Santana. Avenida Universitária, 44031-460 Feira de Santana, Bahia, Brasil. E-mail: fbravo@uefs.br

Revta bras. Zool. 19 (Supl. 2): 181 - 185, 2002 


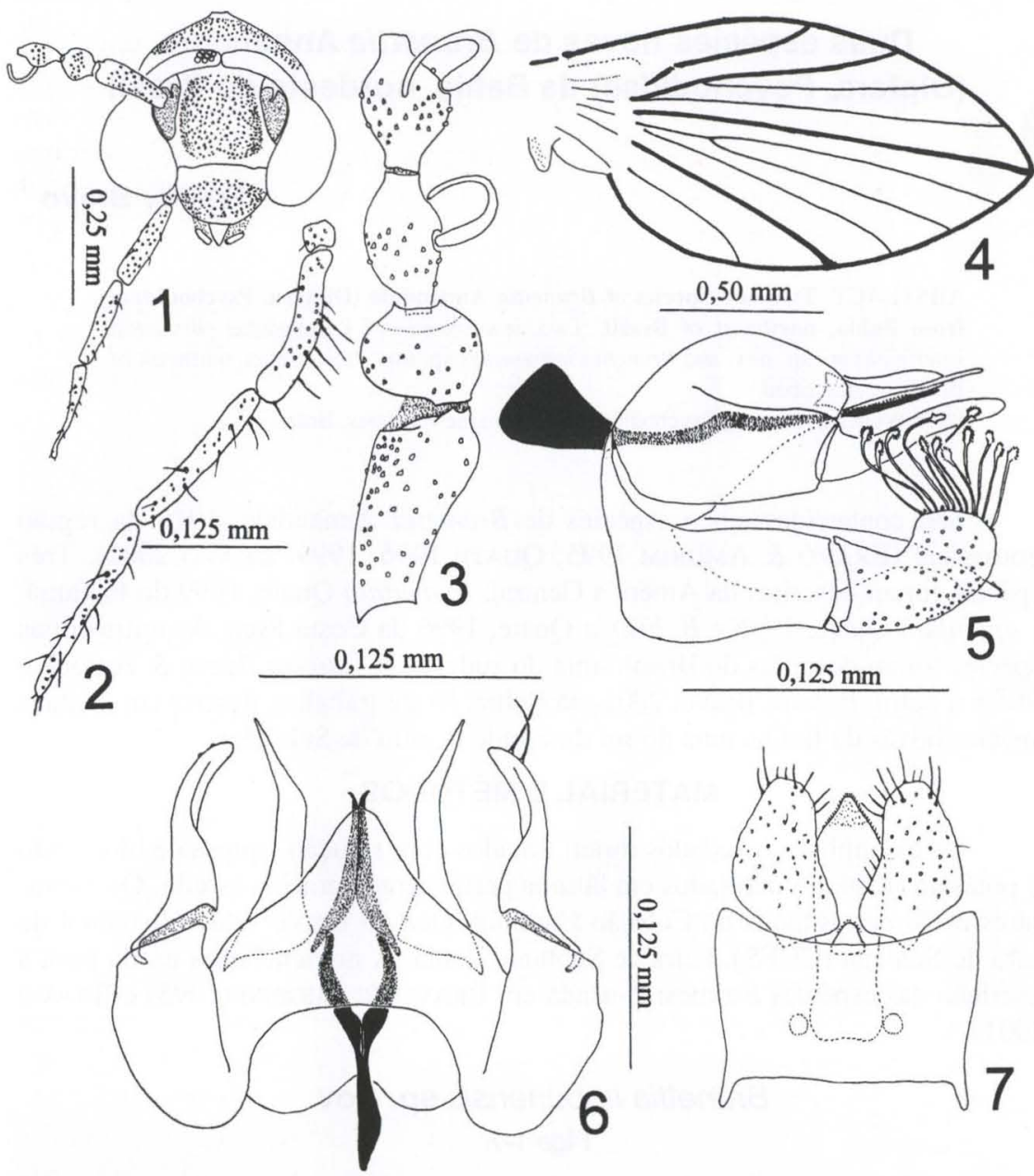

Figs 1-7. Brunettia itabunensis sp. nov., holótipo: (1) cabeça; (2) palpo maxilar; (3) escapo, pedicelo e dois primeiros flagelômeros; (4) asa; (5) terminália masculina, lateral; (6) terminália masculina, dorsal; (7) terminália masculina ventral.

Cabeça. Subcircular (Fig. 1). Ponte ocular completa (Fig. 1). Palpo maxilar com quatro segmentos; comprimento relativo dos segmentos do palpo: 1,0:7,4: 7,8:8,6 (Fig. 2). Antena incompleta; escapo subcilíndrico; pedicelo subesférico; flagelômeros basais excêntricos, com formato de garrafa; ascoides com formato de C (Fig. 3).

Asa. Comprimento, 1,37 mm; largura máxima, 0,68 mm. R5 terminando no ápice. Rs pectinada. $R_{1}$ quebrada na base. $R_{1}, R_{2}, R_{5}$ e $M_{4}$ mais esclerotinizadas que o resto de veias. Sc pouco esclerotinizada, sem cerdas; as outras veias com cerdas. Veias transversais não observadas (Fig. 4). 
Terminália. Tergito 9 , esternito 9 , tergito 10 e gonocoxitos sem pilosidade (Figs 5-7). Esternito $10 \mathrm{com}$ micropilosidade apical (Fig. 7). Cercos com cerdas modificadas no ápice, os tenáculos (Fig. 5). Gonóstilos com duas cerdas grossas apicais (Fig. 6). Tergito 9 subquadrado, com margem distal reta e par de aberturas basais (Fig. 7). Esternito 9 largo fundido com os gonocoxitos; lobo dedial, placa pós-hipandrial, com base larga (Fig. 6). Tergito 10 triangular (Fig. 7). Base e região média do esternito 10 da mesma largura; ápice terminando em ponta (Fig. 7). Gonóstilos subcilíndricos, convergentes (Figs 5, 6). Parâmeros estreitos, largos na base, dobrados apicalmente (Fig. 6). Edeago simétrico, apicalmente bífido (Fig. 6). Apódema edeagal com base larga, subtriangular (Fig. 5). Ponte gonocoxal larga com invaginação na margem proximal (Fig. 6).

\section{Brunettia soteropolitana sp. nov.}

Figs 8-12

Material-tipo. Holótipo macho. BRASIL, Bahia: Salvador, 30.VIII.2001, F. Bravo leg. (CUFS).

Etimologia. O nome da espécie deriva do nome dado aos naturais de Salvador, cidade onde foi coletado o espécime tipo.

Diagnose. Sc e CuA pouco esclerotinizadas. $\mathrm{R}_{1}$ quebrada na base. Placa pós-hipandrial estreita na base. Apice do esternito 10 arredondado. Parâmeros subtriangulares, divergentes. Parâmeros retos. Base do apódema ejaculador larga, subcircular.

Holótipo macho. Tegumento preto. Comprimento do corpo, desde o inicio do tórax até o final do abdôme, 1,64 mm.

Cabeça. Subcircular. Ponte ocular completa. Palpo maxilar perdido durante a coleta. Antena incompleta; escapo subcilíndrico; pedicelo subesférico; flagelômeros basais excêntricos, com formato de garrafa (Fig. 8); ascoides perdidos.

Asa. Comprimento, $1,51 \mathrm{~mm}$; largura máxima, $0,82 \mathrm{~mm}$. $\mathrm{R}_{5}$ terminando no ápice. Rs pectinada. $\mathrm{R}_{1}$ quebrada na base. $\mathrm{R}_{1}, \mathrm{R}_{2}, \mathrm{R}_{5}$ e $\mathrm{M}_{4}$ mais esclerotinizadas que o resto de veias. Sc e CuA pouco esclerotinizadas, sem cerdas; as outras veias com cerdas. veias transversais não observadas (Fig. 9).

Terminália. Tergito 9 , esternito 9 , tergito 10 e gonocoxitos sem pilosidade (Figs 10-12). Esternito 10 com micropilosidade apical (Fig. 12). Cercos com tenáculos apicais (Fig. 10). Gonóstilos com duas cerdas grossas apicais (Fig. 11). Tergito 9 sub-retangular, com margem distal curva e par de aberturas basais (Fig. 12). Esternito 9 estreito fundido com os gonocoxitos; placa pós-hipandrial com base estreita (Fig. 11). Tergito 10 triangular (Fig. 12). Esternito 10 estreito na base mais largo na região média (Fig. 12). Gonóstilos subcilíndricos, convergentes (Figs 10, 11). Parâmeros subtriangulares, retos (Fig. 11). Edeago simétrico, apicalmente bífido (Fig. 11). Apódema edeagal estreito dorsalmente (Fig. 11), com base larga, subcilíndrica (Fig. 10). Ponte gonocoxal larga com margem proximal reta (Fig. 11). 


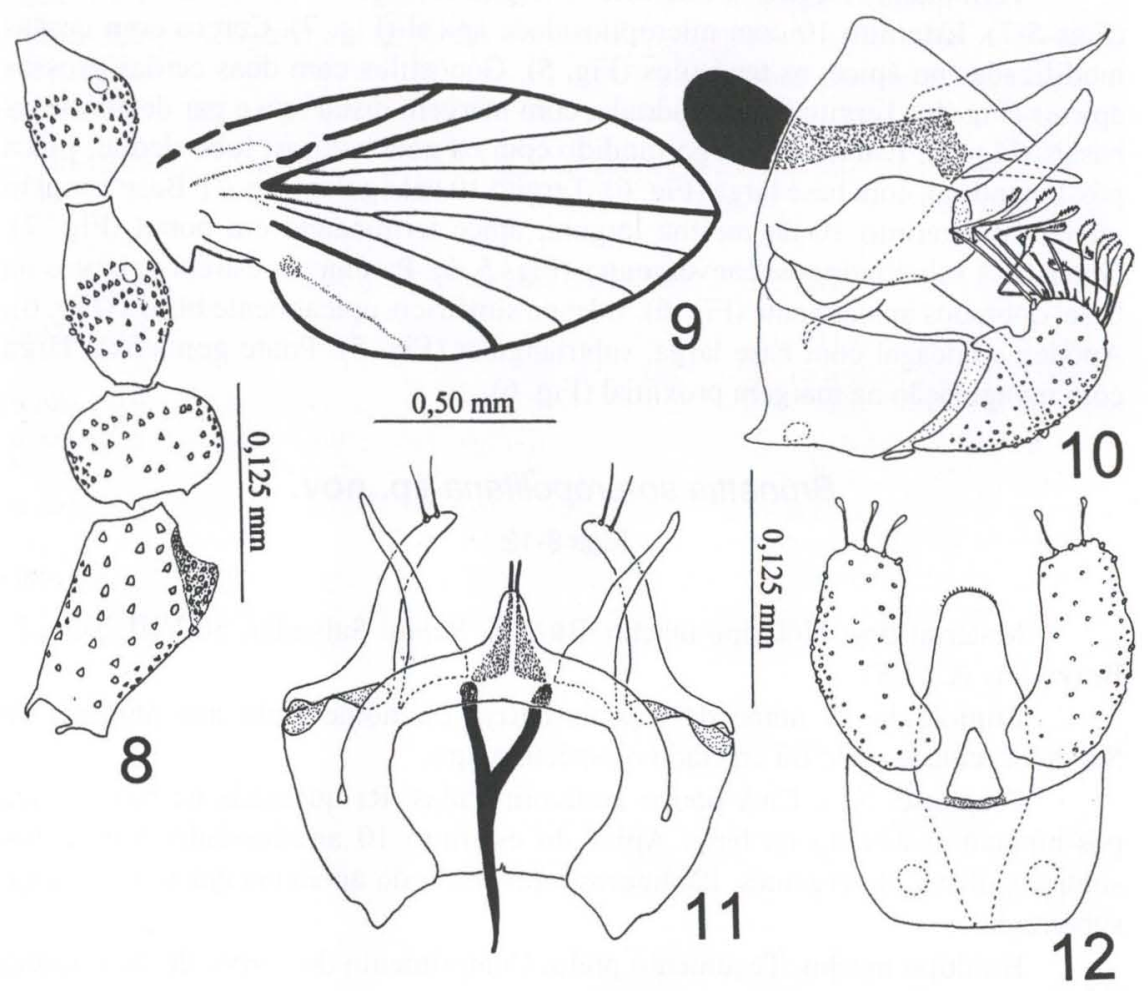

Figs 8-12. Brunettia soteropolitana sp. nov.: (8) escapo, pedicelo e dois primeiros flagelômeros; (9) asa; (10) terminália masculina, lateral; (11) terminália masculina, dorsal; (12) terminália masculina ventral.

\section{DISCUSSÃO}

O subgênero Neobrunettia Bravo \& Amorim, 1995 inclui quatro espécies neotropicais, B. apiculata, B. bistria da Costa Rica, B. bora e B. caipira do Brasil (BRAVO 2001) sendo definido pela pouca esclerotinização da Sc e a falta de cerdas nessa veia. As duas espécies novas da Bahia, B. itabunensis e B. soteropolitana apresentam uma $S c$ pouco esclerotinizada, sem cerdas, o que permite incluí-las neste subgênero.

A presença de uma quebra basal da $\mathrm{R}_{1}$ nas espécies novas $B$. itabunensis e B. soteropolitana é uma característica observada apenas em $B$. caipira, entre as espécies de Neobrunettia. A CuA de B. soteropolitana é pouco esclerotinizada, diferenciando-se, assim, de B. caipira e $B$. itabunensis sp. nov. que possuem uma $\mathrm{CuA}$ normal, com cerdas. B. caipira e B. itabunensis sp. nov. diferenciam-se pelo 
tamanho do primeiro segmento do palpo maxilar, sendo menor em $B$. itabunensis sp. nov., e pelo formato da base do apódema edeagal, subtriangular em $B$. itabunensis sp. nov. e subcilíndrico em B. caipira.

AGRADECIMENTOS. Ao Dr. Jaques Delabie (CEPLAC/ UESC) pelo material de Diptera enviado para estudo.

\section{REFERÊNCIAS BIBLIOGRÁFICAS}

Bravo, F. 2001. Brunettia bora, a new species of moth-fly (Diptera, Psychodidae) from Brazil. Stud. Neotrop. Fauna Environ., Lisse, 36 (3): 211-214.

Bravo, F. \& D.S. Amorim. 1995. First known neotropical species of Brunettia (Diptera: Psychodidae) from southeastern Brazil, with description of a new subgenus and systematic comments on the genus. Iheringia, Ser. Zool., Porto Alegre, (79): 149-158.

QuATE, L.W. 1996. Preliminary taxonomy of Costa Rican Psychodidae (Diptera) exclusive of Phlebotominae. Rev. Biol. Trop., San José, 44 (Suppl. 1): 1-81.

- 1999. Taxonomy of neotropical Psychodidae (Dipter) 3. Psychodines of Barro Colorado Island and San Blas, Panama. Mem. Entomol. Internat., Gainsesville, 14: 409-441.

Recebido em 24.VI.2002; aceito em 27.XI.2002. 